\title{
Resistivity of Fe/Al Multilayered Thin Films from Low Temperature to Room Temperature
}

\author{
Veeranna Kalkori, Santosh Kori, Shweta C, R. Rawat
}

\begin{abstract}
By using electron beam gun and thermal deposition techniques in the vacuum range $6 \times 10-5 m b a r$. The pure materials of $99.99 \%$ purity of iron and aluminium multilayers films grown on glass substrates at $300 \mathrm{~K}$ in the following viz. The resistance was measured using four probe method at UGC-DAE Consortium Indore (4.2K to $300 \mathrm{~K})$ later resistivity, conductivity, temperature co-efficient of resistance (TCR), residual resistivity ratio (RRR), and activation energy (Ea) were calculated. The resistivity behavior shown that the resistivity is increased with increasing the $n$ value, resistivity is increased with increasing temperature. The data belonging to metallic region has been analyzed using the conventional power law's and it is first time this set of films have explore resistivity at low temperature.
\end{abstract}

Key words: thin films, multilayers, RRR, TCR, Power laws

\section{INTRUDUCTION}

The problems of nano structures and nano range thin films have been attracting the researchers because of electron transport with temperature and magnetic effects. It is very important to identify the scattering mechanism for thin films with temperature and magnetic field, Investigations of such objects are of great fundamental importance, because such studies will shed light on the behavior of the electron density of states of such thin layers as well as electrical properties of low dimensional objects for Al films the resistivity decreased with increasing thickness[1] and also it is important for the development of coatings with new predictable properties[2-3]. RRR is also one of tool for scattering mechanism studied in literature for different metals[4-5], The attentiveness of free electrons plays an important role in the depiction of the electrical conductivity in metals as thin films. Discussed in other thin films [6]. TCR values reported for bulk as well as thin films [7].

\section{EXPERIMENTAL METHODS}

FE/Al films were primed with EB gun and thermal techniques at a pressure $6 \times 10^{-5}$ mbar and at $300 \mathrm{~K}$ on glass substrates and these pure elements were procured from M/S Alfa-Aeser, USA. The thickness and the rate of deposition measured using quartz crystal thickness monitor.

Revised Manuscript Received on February 05, 2020.

* Correspondence Author

Veeranna Kalkori*, professor in the department of physics, K.C.T. engineering college, kalaburagi.

Santosh Kori, Associate professor in the department of physics, K.C.T. engineering college, kalaburagi.

Shweta C, Assistant professor in the department of physics, K.C.T engineering college, kalaburagi

R. Rawat, UGC-DAE Consortium for Scientific Research, University Campus Khandwa road,Indore, (M.P.) -452017 (India).

(C) The Authors. Published by Blue Eyes Intelligence Engineering and Sciences Publication (BEIESP). This is an open access article under the CC BY-NC-ND license (http://creativecommons.org/licenses/by-nc-nd/4.0/)
The resistivity measured using four probe method in an oxford instruments make setup in the temperature range $4.2 \mathrm{~K}$ to $300 \mathrm{~K}$ at IUC Indore. While preparing the samples rate of evaporation was mentioned for all the samples as $2 \AA / s$.

The samples are $[\mathrm{Fe}(10 \AA) / \mathrm{Al}(10 \AA)]_{\mathrm{N}} \quad \mathrm{N}=1,3,6,9$ and 12 Named as FA1, FA2, FA3, FA4 and FA5. And the resistance measured from $4.2 \mathrm{~K}$ to $300 \mathrm{~K}$.

\section{RESULTS AND DISCUSSIONELECTRICAL RESISTANCE}

The resistivity is increased with temperature of their interest for these films. The room temperature $(300 \mathrm{~K})$ resistivity $\rho$, was less by three or four orders of magnitude than the bulk. may be due to increasing of the layer thickness. Also observed that the resistivity is decreased with thickness of the layers in the range $2.2 \times 10^{-4}$ to $2.03 \times 10^{-2}(\Omega \mathrm{m})$. The variation of $\rho$ with temperature $T$ is shown in fig1. The resistivity increased slowly with increasing temperature. The spin as well as lattice waves get excited as the temperature is increased which results in the enhanced electron-phonon scattering. These caused increase of total resistivity.
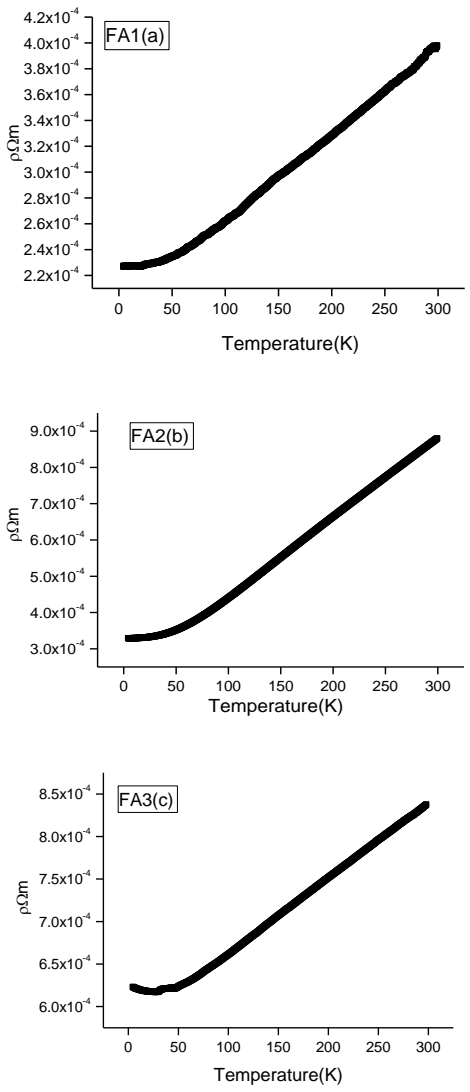

Published By: 

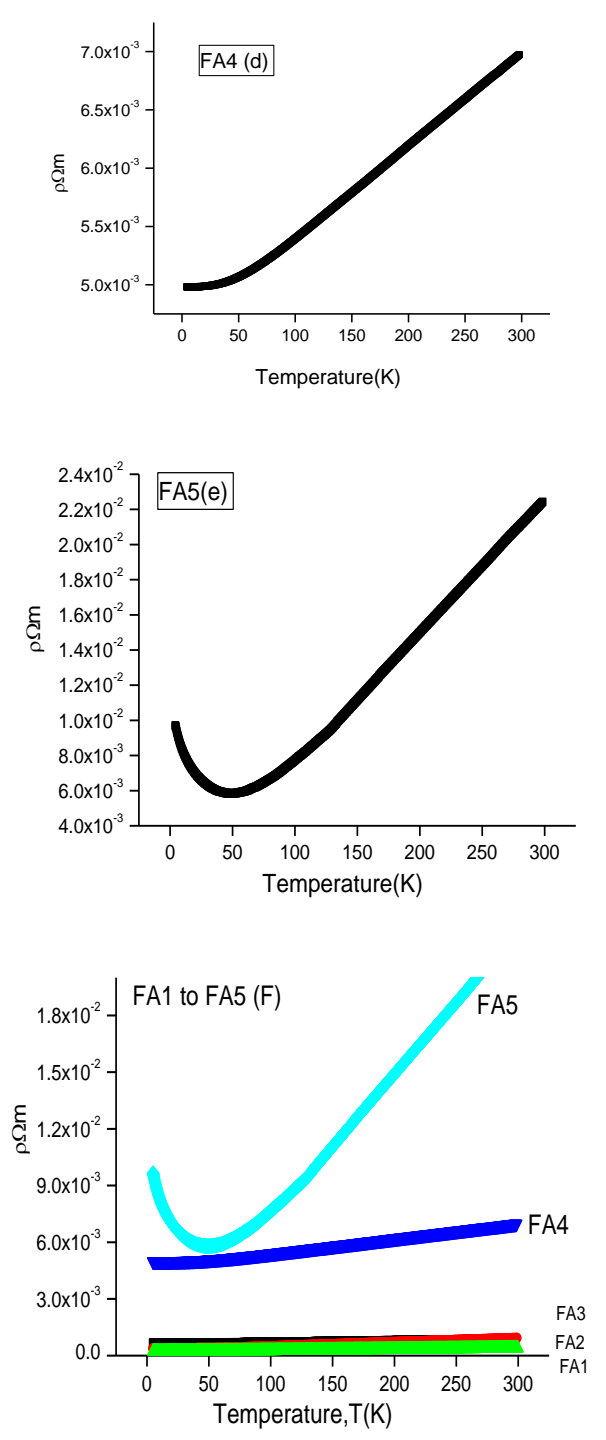

Fig:1. Plots of Resistivity, $\rho$, versus temperature range 5 to300K.

As per the conductivity expression, $\sigma=\sigma_{0} \exp \left(\mathrm{E}_{\mathrm{a}} / \mathrm{K}_{\mathrm{b}} \mathrm{T}\right)$ the plots of $\ln (\sigma)$ versus $(1000 / T)$ were sketched and shown in fig .2. Here, $E_{a}$ stands for activation energy for $d c$ conduction. The $\mathrm{E}_{\mathrm{a}}$ for each film has been determined by fitting least square linear lines in the temperature range 200 to $300 \mathrm{~K}$ and obtained values are tabulated in table 1 .

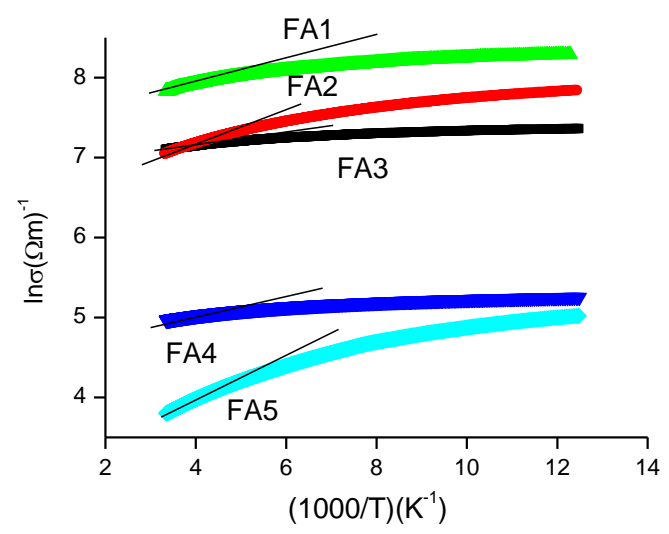

Fig. 2: The plots of $\ln (\sigma)$ versus (1/T). The lines Drawn are the least square linear fits to the data in the temperature range 200 to $300 \mathrm{~K}$.
The residual resistivity ratio RRR of the films has been estimated as $R R R=\left(R_{300 K} / R_{30 K}\right) * 100$. Present sample's the RRR are in the range of 28 to 73.these values may be due to the enhanced grain boundary for metals, The temperature coefficient of resistance (TCR) is the parameter which confirms relationship between electrical resistance and temperature. TCR has been determined in the temperature range $80 \mathrm{~K}$ to $300 \mathrm{~K}$ as $\mathrm{TCR}=\left\{(\mathrm{d} \rho / \mathrm{dT}) / \rho_{\mathrm{s}}\right\}$ where $\rho_{\mathrm{s}}$ is room temperature resistivity and the TCR values are in the range of $10^{-3}\left(\mathrm{~K}^{-3}\right)$. The RRR and TCR values are in the range of the reported in the literature.TCR values are positive and it is observed that TCR values are increasing with increasing number of layers in FA3, FA4 and FA5 films, it may be due to the increasing mobility of metal carrier when temperature increases, which means the higher temperature the greater resistance. The resistance of bulk metals usually increases monotonically with temperature due to electron-electron scattering, [8]. $\mathrm{E}_{\mathrm{a}}$, RRR, and TCR values are tabulated in table 1.

Table 1., RRR, TCR and Activation energy, $E_{a}$.

\begin{tabular}{|c|c|c|c|}
\hline $\begin{array}{c}\text { Sample } \\
\text { No }\end{array}$ & $\begin{array}{c}\mathrm{E}_{\mathrm{a}}(\mathrm{eV})(200 \\
\text { to 300K) }\end{array}$ & RRR(30To300K) & $\begin{array}{c}\mathrm{TCR}\left(\mathrm{K}^{-1}\right) \\
(80 \mathrm{To} 00 \mathrm{~K})\end{array}$ \\
\hline FA1 & $1.01 \times 10^{-5}$ & $5.75 \times 10^{1}$ & $1.69 \times 10^{-3}$ \\
\hline FA2 & $1.48 \times 10^{-5}$ & $3.85 \times 10^{1}$ & $2.52 \times 10^{-3}$ \\
\hline FA3 & $5.72 \times 10^{-6}$ & $7.37 \times 10^{1}$ & $1.06 \times 10^{-3}$ \\
\hline FA4 & $6.27 \times 10^{-6}$ & $7.16 \times 10^{1}$ & $1.15 \times 10^{-3}$ \\
\hline FA5 & $2.13 \times 10^{-5}$ & $2.80 \times 10^{1}$ & $3.33 \times 10^{-3}$ \\
\hline
\end{tabular}

The measured resistivity $\rho$ versus temperature is shown in figure.1 for film thicknesses ranging from 2 to $24 \mathrm{~nm}$. the temperature dependence of resistivity has been considered by dividing the entire temperature range into three intervals take two intervals that is $\mathrm{T}=5$ to $80 \mathrm{~K}$ and $\mathrm{T}=80$ to $300 \mathrm{~K}$ It can be observed that the resistivity of all films is linear in the temperature range of $80-300 \mathrm{~K}$ and the power laws of the type $\rho(\mathrm{T})=\mathrm{A}+\mathrm{B}^{\mathrm{n}}$ have been used and best fit coefficients have been extracted in the temperature range 80-300 K shown in fig.3. And fitting parameters A,B and $\mathrm{n}$ are shown in table 2 . The exponent $n$ was found to be one in all the films establishing a linear relation between resistivity and temperature in the temperature range 80 to $300 \mathrm{~K}$. the coefficients A and B are found to be in the orders of $10^{-4}$ to $10^{-6} \Omega \mathrm{m}$.
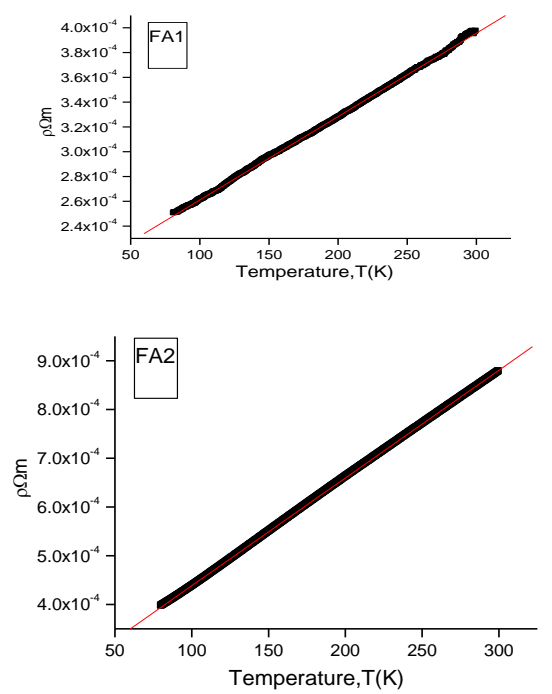

Published By:

Blue Eyes Intelligence Engineering \& Sciences Publication 

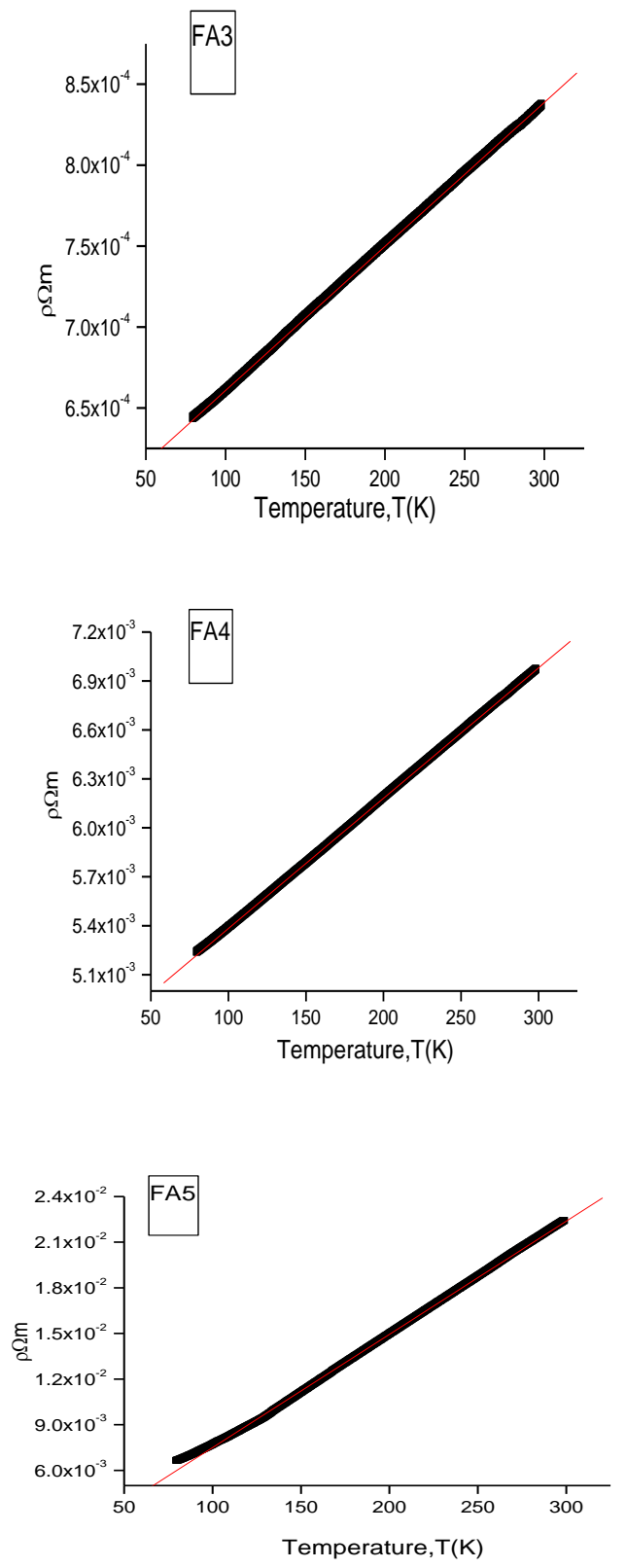

Fig: 3 Plot of resistivity, $\rho$ versus Temperature, $T$ in the range 80 to $300 \mathrm{~K}$ for thin films

Table 2.fitting parameters $A, B$, and $n$ values in the temperature range 80 to $300 \mathrm{~K}$.

\begin{tabular}{|c|c|c|c|}
\hline Sample No & $\mathrm{n}$ & $\mathrm{B}$ & $\mathrm{A}$ \\
\hline FA1 & & $1.93721 \times 10^{-4}$ & $6.73257 \times 10^{-7}$ \\
\hline FA2 & 1 & $2.17222 \times 10^{-4}$ & $2.21135 \times 10^{-6}$ \\
\hline FA3 & 1 & $5.71757 \times 10^{-4}$ & $8.90246 \times 10^{-7}$ \\
\hline FA4 & 1 & $4.58000 \times 10^{-3}$ & $7.98798 \times 10^{-6}$ \\
\hline FA5 & 1 & $5.26263 \times 10^{-5}$ & $7.44392 \times 10^{-5}$ \\
\hline
\end{tabular}

When we ploted the graph resistance versus temperature in the range 5 to $80 \mathrm{~K}$ as shown in fig 4 it can be observed that the resistivity is decreased with increasing temperature in FA3 and FA5 that is semiconductor to metallic transition in films up to 30 and $50 \mathrm{~K}$ respectively and in all films we can find only metallic behavior in temperature range 50 to $80 \mathrm{~K}$.
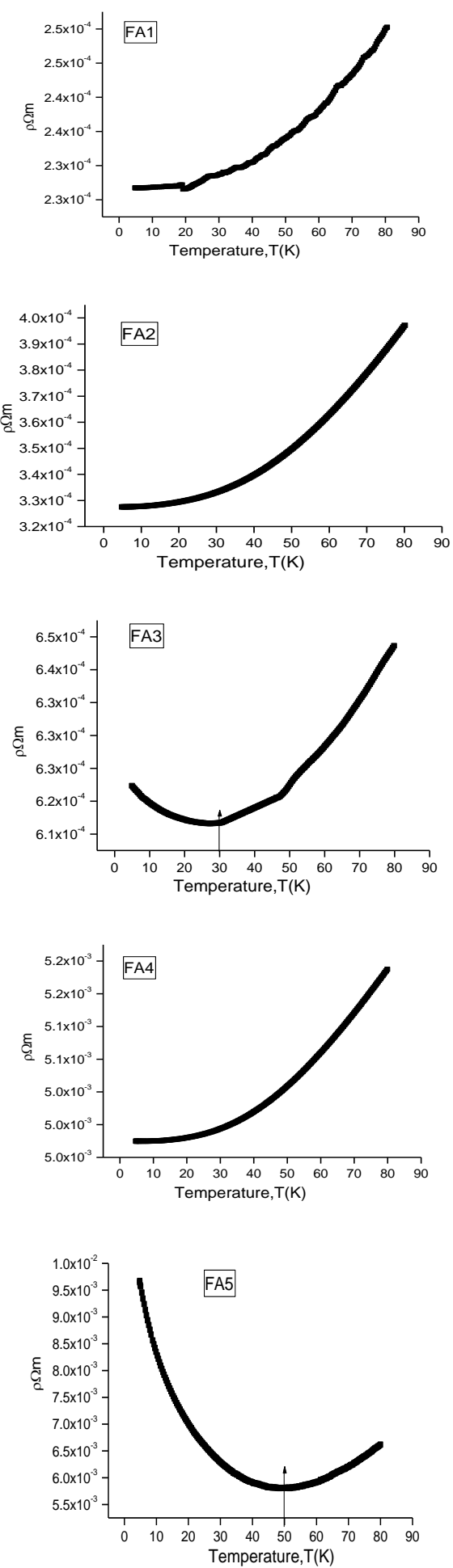

Fig.4. Plots of resistivity, $\rho$ versus temperature, $T$ for the films FA1,FA2,FA3,FA4 and FA5 in the range 5 to $80 \mathrm{~K}$ Therefore for the consistency we have analyzed all films 50 to $80 \mathrm{~K}$ data using the power law's that is $\rho(\mathrm{T})=\mathrm{A}+\mathrm{B}^{\mathrm{n}}$ in the temperature range 50 to $80 \mathrm{~K}$ (as shown in Fig 5.) In the temperature range $50 \mathrm{~K}$ to $80 \mathrm{~K}$ the best fit coefficients have been extracted in the temperature ranges and shown in table 3. The linear relation between resistivity and temperature broke the exponent values determined in this range of temperature is much above the unity.

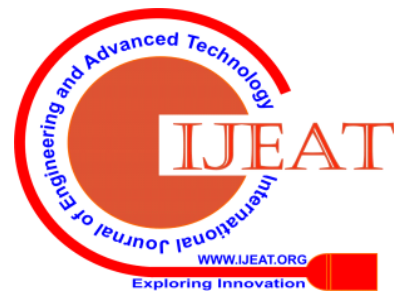


Coefficients B and A were in the order of $10^{-4}$ to $10^{-10} \Omega \mathrm{m}$ the temperature below $80 \mathrm{~K}$ the electron phonon $\mathrm{s}-\mathrm{d}$ scattering[9-10] $\mathrm{T}^{3}$ term called block willsion term begins has been said to dominate over the electron-magnon $\mathrm{T}^{\mathrm{n}}$ term. For our samples, the exponent is found to be between 2 and 3.5. The observed differences between the $n$ value infer that the interfaces between the layers and the magnetic layers thickness also affect the temperature dependence of resistivity in addition to the contributions from electronphonon-magnon scatterings.
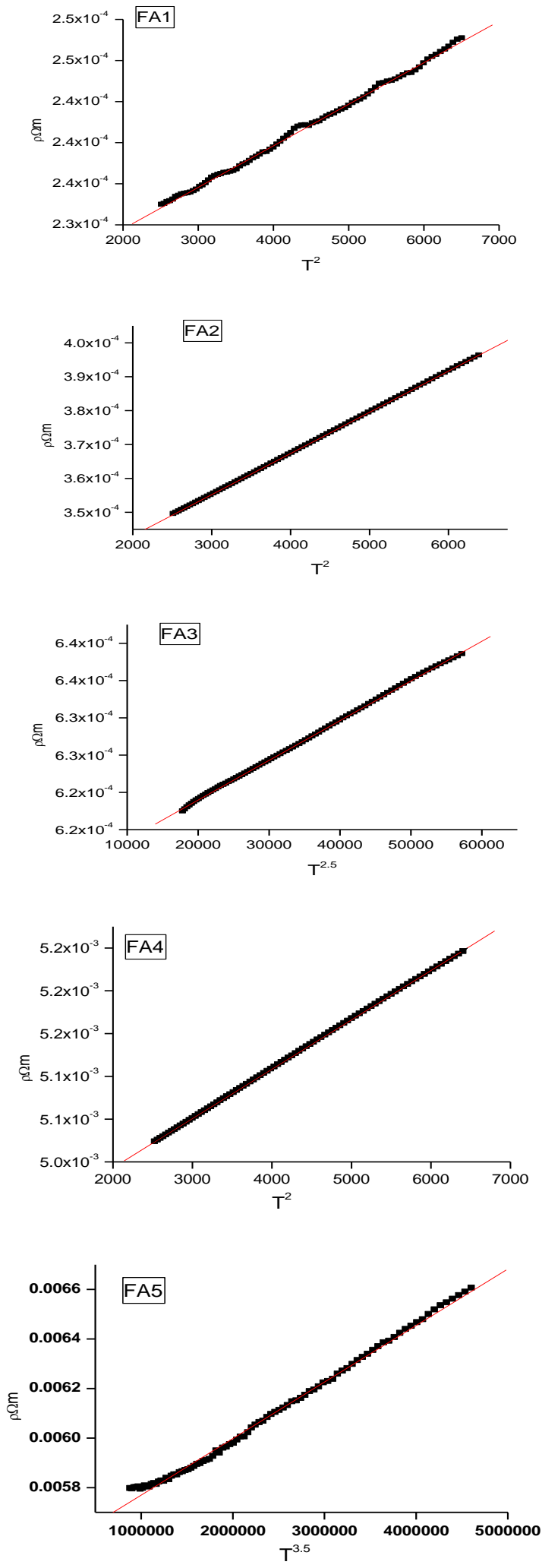

Fig.5. Plots of resistivity versus temperature power dependence of FA1,FA2,FA3,FA4 and FA5 in the temperature range 50 to $80 \mathrm{~K}$

Table 3. Temperature power and the fitting parameters $A, B$ and $n$ values in the temperature range 50 to $80 \mathrm{~K}$

\begin{tabular}{|c|c|c|c|}
\hline Sample name & $\mathrm{n}$ & $\mathrm{B}$ & $\mathrm{A}$ \\
\hline FA1 & 2 & $2.23 \times 10^{-4}$ & $4.04 \times 10^{-9}$ \\
\hline FA2 & 2 & $3.18 \times 10^{-4}$ & $1.21 \times 10^{-8}$ \\
\hline FA3 & 2.5 & $6.13 \times 10^{-4}$ & $5.32 \times 10^{-10}$ \\
\hline FA4 & 2 & $4.94 \times 10^{-3}$ & $4.60 \times 10^{-8}$ \\
\hline Fa5 & 3.5 & $5.54 \times 10^{-3}$ & $2.28 \times 10^{-10}$ \\
\hline
\end{tabular}

The thickness dependence of the resistivity and the films can be satisfactorily interpreted with the help of the statistical model. Hence basic assumptions of this seem to be justified. Evidently, a reduction of the geometric cross-section for the conduction paths and the island formation are responsible for the strong increase of resistivity with increase of temperature and free electrons in the conduction band and these free electrons increase electrical conductivity. In our samples the resistivity is increased with increasing temperature and the repetition of the layers the resistivity of the present films are in the range reported for other multilayer films [11]. The resistivity is increased slowly with increasing temperature. The spin as well as lattice wave gets excited as the temperature is increased which results in the enhanced electron-magnon and electron-phonon scatterings. These are reflected in the increase of total resistivity with increase of temperature in these samples.

\section{CONCLUSION}

The temperature dependence of resistance for $\mathrm{Fe} / \mathrm{Al}$ from $300 \mathrm{~K}$ to $5 \mathrm{~K}$ can be analyzed, The structural properties of the thin film undoubtedly contribute greatly to RRR values. The RRR obtained in the temperature range 30 to $300 \mathrm{~K}$ and TCR were worked out in the range 80 to $300 \mathrm{~K}$, and the high temperature activation energy were calculated in the temperature range 200 to $300 \mathrm{~K}$. again for the conductivity analyzes the entire temperature range is divided in to two ranges that is 50 to $80 \mathrm{~K}$ and 80 to $300 \mathrm{~K}$, in the temperature 80 to $300 \mathrm{~K}$ the power's laws of the type $\rho(T)=A+B^{n}$ has fit and the parameters $\mathrm{A}, \mathrm{B}$ and $\mathrm{n}$ were extracted. Power laws of type $\rho(T)=A+B^{n}$ were invoked in the range 50 to $80 \mathrm{~K}$ for all five films and constants $\mathrm{A}, \mathrm{B}$ and $\mathrm{n}$ were extracted. Temperature dependent resistivity of these multilayered films is evidently connected to electronphonon scattering, In Fe/Al multilayered films small change in the resistivity is because of small bridge layers of the iron between aluminium layers.

\section{ACKNOWLEGEMENTS}

Dr. Santosh Kumar strongly acknowledges to VGST for financial assistance for procuring the material, Vacuum coating unit, and electron beam gun and accessories for making a sample preparation set up under the scheme CISEE with GRD No. 328 and SMYSR with GRD No 392.
Published By:

Blue Eyes Intelligence Engineering \& Sciences Publication 


\section{REFERENCE}

1. Erica Pereira Da Silva, Michel Chaves, Steven Frederick Durrant Materials Research 17(6), 1384-1390(2014)

2. F. Matino, L. Persano, V. Arima, D. Pisignano, R.I.R. Blyth, R. Cingolani, Ross Rinaldi, Phys. Rev. B 72 (2005) 085437.

3. J. Ederth, P. Johnsson, G.A. Niklasson, A.Hoel,A.Hultaker, P.Heszler, C.G. Granqvist,A.R. van Doorn, M.J. Jongerius, D. Burgard, Phys. Rev. B 68 (2003) 155410.

4. A. Gupta, X. W. Li, and G. Xiao, J. Appl. Phys. 87, 6073 2000!.

5. X. Li, A. Gupta, and G. Xiao, Appl. Phys. Lett. 75, 713 1999!.

6. P. Grosse in Free Electrons in Solids [Russian translation], Mir, Moscow (1982), Chap. 6, p. 49.

7. Kim, S., Suhl, H., Schuller, I.K. Surface phonon scattering in the electrical resistivity on $\mathrm{Co} / \mathrm{Ni}$ superlattices. Phys. Rev. Lett. 78, 322 \{325 (1997). DOI: 10.1103/PhysRevLett.78.322

8. D. Schumacher, surface scattering with conduction electrons, Tracts in Modern Physics, V128, Springer Verlag, Berlin, 1993

9. S. K. Srivastva, R. Kumar, A. Gupta. R.S Patel. A> K. Mujumdar. And D. K. Avasthi.Nucl. Instr. And Meth. B. 243:304(2006)

10. D.A. Goddings, Phys. Rev. 132:542(1963).

11. Hotovy I, Huran J, Spiess L, Liday J, Sitter H, Hascik S (2003) Vacuum) 69:237.

\section{AUTHOR S PROFILE}

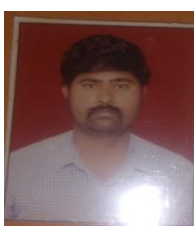

Veeranna Kalkori M.Sc, Thin films. Working as a assistant professor in the department of physics, K.C.T. engineering college, kalaburagi

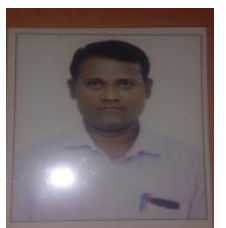

Santosh Kori ${ }^{\mathbf{a}}$ M.Sc. Ph.D. more than 14 publications, glasses and thin films, ISCA life member, Sanctioned VGST CISEE with GRD No. 328 and SMYSR with GRD No 392 projects, and working as Associate professor in the department of physics, K.C.T. engineering college, kalaburagi.

Shweta C M.Sc, Thin films.Working as a assistant professor in the department of physics, K.C.T. engineering college, kalaburagi

R. Rawat UGC-DAE Consortium for Scientific Research, University Campus Khandwa road,Indore, (M.P.) -452017 (India). 